\title{
Doğal Kaynak Zenginliği ve Ekonomik Büyüme illişkisinde Yönetişim Göstergelerinin Aracılık Etkisi: MENA ve Hazar Ülkelerinden Ampirik Bulgular
}

\author{
Mediation Effect of the Governance Indicators in the Natural Resources Abundance and \\ Economic Growth Relationship: Empirical Evidence from the MENA and Caspian Countries
}

Emrah Eray AKÇA ${ }^{1}$, Harun $\mathrm{BAL}^{1}$, Mehmet DEMIRAL ${ }^{2}$

\begin{abstract}
ÖZET
Bu çalışma, Orta Doğu-Kuzey Afrika (MENA) ve Hazar bölgesinden 21 ülke $(N=21)$ için, doğal kaynak zenginliği ve ekonomik büyüme ilişkisinde yönetişim göstergelerinin aracılık etkisini, 1996-2012 dönemi yıllık dengeli panel verileri $(T=17)$ kullanarak incelemektedir. Bu kapsamda, kişi başına ham petrol üretiminin kişi başına reel GSYH üzerine etkisi tahmin edildikten sonra, bu ilişkide kurumsal-temelli yönetişim göstergelerinin aracılık rolünü belirlemek için hiyerarşik regresyon analizi uygulanmıştır. İkili regresyon tahmin sonuçları, kişi başına ham petrol üretimi ile genel olarak küresel yönetişim göstergeleri arasında negatif bir ilişki olduğunu ve yönetişim göstergelerinin tüm boyutlarında meydana gelen gelişmelerin kişi başına reel GSYH'yı artırdığını göstermektedir. Hiyerarşik regresyon sonuçları, ham petrol üretimi ve kişi başına reel GSYH arasındaki ilişkide yönetişim göstergelerinin, kısmi bir aracı değişken olarak, önemli bir rol oynadığını göstermektedir. Bu bulgu, doğal kaynak zenginliğinin ekonomik büyümeyi artırmasının, bu zenginliğinin aynı zamanda yönetişim göstergelerini bozması nedeniyle engellenme eğiliminde olduğunu ortaya koymaktadır. Tüm sonuçlar, kurumsal niteliği geliştirecek demokratik, politik ve hukuki düzenlemeler ile birlikte yolsuzluğu ve şiddeti önlemeye yönelik bütünleşik politikaların önemine dikkat çekmektedir.
\end{abstract}

Anahtar Kelimeler: Ham petrol üretimi, ekonomik büyüme, küresel yönetişim göstergeleri, aracılık etkisi, hiyerarşik panel regresyon analizi.

\section{GiRiş}

Doğal kaynak zenginliğinin ekonomik büyüme üzerine etkileriyle ilgili temelde iki farklı yaklaşım bulunmaktadır. Birinci yaklaşımda, zengin doğal kaynak donanımı ülke ekonomisi için bir nimet (blessing) olarak değerlendirilirken, ikinci yaklaşımda ise bir talihsizlik (curse) olarak görülmektedir (bkz. Sachs ve Warner, 1997, 1999, 2001; Gylfason, 2001; Lederman ve Maloney, 2007). Birinci yaklaşımda, zengin doğal kaynaklara sahip olan ülkelerin daha hızlı büyüme performansı göstermesi beklenirken, ikinci yaklaşım

\begin{abstract}
This study investigates the mediation effect of the governance indicators in the relationship between natural resources abundance and economic growth for 21 countries $(\mathrm{N}=21)$ from Middle East-North Africa (MENA) and Caspian regions, using 1996-2012 balanced annual ( $T=17)$ panel data sets. In this context, after estimating the impact of crude oil production per capita on real GDP per capita, hierarchical panel regression analysis is conducted to determine the mediation role of the institutions-based governance indicators in this relationship. Results from the pairwise regression estimations reveal that crude oil production per capita is negatively associated with worldwide governance indicators in general and the progressive improvements in all dimensions of governance indicators seem to promote the real GDP per capita growth. Results from the hierarchical regressions demonstrate that governance indicators play an important role as a partial mediator in the relationship between crude oil production and real GDP per capita. This evidence supports that governance indicators, weakened by natural resources abundance, tend to hinder natural resources abundance to contribute economic growth. Overall findings highlight the importance of integrated policies intended for preventing the corruption and violence, together with democratic, political and legal regulations to improve the institutional quality.
\end{abstract}

Keywords: Crude oil production, economic growth, worldwide governance indicators, mediation effect, hierarchical panel regression analysis.

zengin doğal kaynak donanımının büyümeyi engelleyici etkilerinin olduğunu öne sürmektedir. 1950'li yıllardan sonra gelişmekte olan ülke (GOÜ)'ler üzerine bazı çalışmalar, doğal kaynak donanımı ve ekonomik büyüme arasındaki ilişkide açık bir paradoksa işaret etmektedir. Bu paradoks, doğal kaynak bakımından zengin olan ülkelerin, nispeten daha az kaynağa sahip ya da kaynak yoksunu olanlarla karşılaştırıldığında, daha düşük büyüme oranlarına sahip olduklarını ifade etmektedir. Bu durum, 'kaynak talihsizliği' terimi ile literatüre girmiştir. 
Doğal kaynak zenginliğinin bir talihsizlik olduğu tartışmaları, özellikle 1970 ve 1980 'li yıllarda daha belirgin bir şekilde gündeme gelmeye başlamıştır. Doğal kaynak talihsizliğinin nedenleri ve aracı değişken mekanizmaları kapsamında çalışmaların bir kısmı, Hollanda hastalığı gelişim kanallarını incelerken (bkz. Lederman ve Maloney, 2007), bazıları kurumsallaşmanın önemine dikkat çekmişlerdir (bkz. Oomes ve Kalcheva, 2007; Pessoa, 2008). İkinci durumda, doğal kaynak zenginliğinin, mevcut kaynaklar üzerinde bir kontrol mücadelesi ve iç huzursuzluğa neden olarak kötü kurumsallaşmaya ve dolayısıyla daha düşük büyümeye yol açtığı üzerinde durulmaktadır. Burada, doğal kaynaklardan elde edilen büyük rantların hükümetleri ve özel kuruluşları rant kollamaya, yozlaşmaya ve yolsuzluğa yöneltmesi vurgulanmaktadır. Buna göre doğal kaynak zenginliğinin ekonomik büyümeyi teşvik etmesi biçimindeki doğrudan pozitif etki, doğal kaynak zenginliğinin aynı zamanda kurumsal yapıları bozması ile gelişen olumsuz dolaylı etkiler nedeniyle azalabilmekte ya da ortadan kalkabilmekte ve hatta negatif bir etkiye dönüşebilmektedir. Bir başka deyişle gelişen bu ilişkilerde yönetişim göstergelerinin olumsuz aracı etkileri belirleyici olmaktadır. Mevcut literatürde bir taraftan kaynak talihsizliği ele alınırken, diğer taraftan kaynak zenginliğinin ülkelerin kurumsal yapısını bozma kanalları incelenmekte, ancak bu iki ilişkinin birlikte etkileşiminin ihmal edildiği görülmektedir.

Doğal kaynak zenginliğinin ekonomik büyüme performansını tek başına belirlemekten uzak olduğu, özellikle kaynak donanımı bakımından yoksun olan Doğu Asya bölgesi ile doğal kaynakların bol olduğu MENA, Latin Amerika ve Hazar bölgesinden GOÜ'lerin karşılaştııımasına dayanmaktadır (bkz. Demiral, 2014). 1960 'lardan sonra, Doğu Asya'da aşamalı olarak gelişen yüksek büyüme oranları ile kurumsal gelişme trendleri birlikte görülürken, doğal kaynak zengini özellikle MENA ve Hazar bölgesi ülkelerinin düşük büyüme oranları ile kötü kurumsal ve yönetişim göstergelerinin birlikte seyretmesi dikkat çekmektedir. Bu nedenle MENA ve Hazar bölgesi ülkeleri için petrol zenginliği, yönetişim, kurumsal gelişme ve ekonomik büyüme ilişkilerinde doğrudan-dolaylı ve olumlu-olumsuz etkilerin birlikte incelenmesi gerekliliği kendini göstermektedir. Bu da, nispeten az kullanılan aracılık etkisi modellerine dayalı hiyerarşik regresyon analizlerine işaret etmektedir.

Literatürdeki bu gereklilikten hareketle çalışmada, kişi başına ham petrol üretimi ile temsil edilen doğal kaynak zenginliğinin, kişi başına reel GSYH ile ölçülen ekonomik büyümeye olan etkileri, küresel yönetişim göstergelerinin aracılık rolü kapsamında incelenmektedir. Dolayısıyla, ekonomik büyümenin fiziki-beşeri sermaye, işgücü ve teknolojik gelişme gibi sayıları artırılabilen başka belirleyicileri tartışmalarına girilmemiştir. Bu amaçla, Baron ve Kenny (1986)'nin klasik aracılık ilişkisi yaklaşımından hareketle hazırlanan çaIışmada ilk olarak, teorik açıklamalar ve seçilen 1990 sonrası ampirik çalışmalardan özet bir literatür değerlendirmesi sunulmaktadır. Sonrasında, ampirik model ile veri setleri ve analiz prosedürü açıklanmaktadır. Ulaşılan ampirik bulgular ortaya konulduktan sonra çalışma, sonuçlara ilişkin özet değerlendirmeler ile tamamlanmaktadır.

\section{LITERATÜRÖZETI:TEORIKAÇIKLAMALAR VE AMPIRIK BULGULAR}

Geleneksel yaklaşımda, sezgisel olarak bir ülkenin üretim faktörlerindeki artışın ekonomik büyümeye katkı sağlaması beklenmektedir. Bununla birlikte, doğal kaynak zenginliğinin ekonomik büyümeyi farklı kanallardan engellediğini ortaya koyan çalışmalar geniş bir literatür oluşturmuştur (Sachs ve Warner, 1997, 1999, 2001; Gelb, 1988; Gylfason vd., 1999; Bulte vd., 2005). Özellikle 1960 'lardan itibaren kaynak zengini GOÜ'lerin nispeten kaynak yoksunu olan GOÜ'lere göre daha yavaş bir şekilde büyüdüklerini ampirik olarak ortaya koyan çalışmalarla birlikte bu paradoksal bulgu, 'kaynak talihsizliği' ifadesiyle literatüre girmiştir (bkz. Lederman ve Maloney, 2007). Çalışmalardan bazıları doğal kaynak talihsizliğinin, Hollanda hastalığı başta olmak üzere nedenlerine ve gelişim kanallarına odaklanırken, bazıları kurumsal ve yönetişim göstergelerinin etkilerini ayrıca incelemişlerdir.

\subsection{Doğal Kaynak Talihsizliği, Gelişim Kanalları ve Hollanda Hastalığı Açıklamaları}

Kaynak talihsizliğinin gelişim kanalları bakımından bozulan ticaret hadlerine dikkat çeken Singer (1950) ve Prebish (1950) tezi ile Bhagwati (1958)'nin yoksullaştıran büyüme tezi ön plana çıkmaktadır. Teorik açıklamalar ise Rybczynski (1955) teoremi'ne kadar gitmektedir. Rybczynski teoremi'ne göre, mal fiyatları sabitken, üretim faktörlerinden birinin donanımı ya da arzındaki bir artış (azalış) o faktörü yoğun olarak kullanan sektörlerde üretimi mutlak olarak artırırken (azaltırken), diğer sektörlerin üretimi mutlak olarak azalacaktır (artacaktır). Bunun uygulamadaki örneği Hollanda hastalığı'dır: 1960'lı yıllarda Hollanda'da doğal gaz arzının artmasıyla, diğer sanayilerdeki faktörleri çeken doğal gaz sektörlerinde üretim ve ihracat artarken, diğer sanayilerin (özellikle imalat sanayilerinin) daralmıştır (Feenstra, 2004: 18-22). Kaynak talihsizliğinin temel nedenleri arasında gösterilen Hollanda hastalığı hipotezi'ne göre, imalat sanayilerinde görülen gerileme, büyümeyi de yavaşlatmaktadır.

Kaynak talihsizliği durumunda durgun bir büyümeye karşlık ihracat çeşitlendirmesi; Hollanda hastalığı durumunda ise, ekonominin genel olarak büyümesine karşın, imalat sanayilerinin ciddi bir şekilde daralması söz konusudur. Kaynak talihsizliği ve Hollanda hastalığı́nın aynı anda görüldüğü durumda ise durgun büyüme ve imalat sanayisinin daralması birlikte gerçekleşmektedir. Kaynak talihsizliği ve onun temel açıklamalarından olan Hollanda hastalığı'nın etkileri aşağıda Tablo 1'de karşılaştırmalı olarak özetlenmektedir. 
Tablo 1: Kaynak Talihsizliği ve Hollanda Hastalığı Karşılaştırması

\begin{tabular}{|c|c|c|c|}
\hline \multirow{4}{*}{$\begin{array}{c}* \\
\text { Hollanda } \\
\text { Hastalığı }\end{array}$} & Etkiler & Yok & \multicolumn{2}{c|}{ Kaynak Talihsizliği } \\
\cline { 2 - 4 } & Yok & $\begin{array}{c}\text { Ekonomide genel büyüme ve ihracat } \\
\text { farklılaştırması }\end{array}$ & $\begin{array}{c}\text { Ekonomide durgun büyüme, fakat ihracat } \\
\text { farklılaştırması }\end{array}$ \\
\cline { 2 - 4 } & Var & $\begin{array}{c}\text { Ekonomide genel büyüme, fakat imalat } \\
\text { sanayilerinde ciddi daralma }\end{array}$ & $\begin{array}{c}\text { Ekonomide durgun büyüme ve imalat } \\
\text { sanayilerinde ciddi daralma }\end{array}$ \\
\hline
\end{tabular}

(Kaynak: Larsen, 2006: 612).

Illgili literatürde kaynak talihsizliğinin belirtilerinin, etkilerinin ve sonuçlarının farklı göstergeler üzerinden yoğun bir biçimde ele alındığı görülmektedir. Lal (1993), genel olarak, kaynak zengini ülkelerin düşük büyümeye yol açan politikalar izledikleri ve doğal kaynak yoksunu olan ülkelerin daha hızı bir gelişme süreci yaşadıkları sonucuna ulaşmıştır. Gelb (1988) petrol ihracatçısı ülkeleri ele aldığı çalışmasında, doğal kaynak ihracatından elde edilen yüksek gelirlerin refahta düşüşe yol açtığı paradoksuna dikkat çekmiştir. Sachs ve Warner (1999), Latin Amerika ülkelerinde doğal kaynak sektöründe meydana gelen bir canlanmanın, genellikle kişi başına GSYH'da azalmayla birlikte gerçekleştiği sonucuna varmışlardır. Sonrasında Leite ve Weidman (1999), Gylfason (2001) ve Bulte vd. (2005) yaptıkları çalışmalarda farklı ülkeler için kaynak talihsizliği bulgularını destekler biçimde, doğal kaynak bolluğu ve ekonomik büyüme arasında negatif bir ilişki bulmuşlardır. Caselli (2006), 1950'li yılların sonunda Nijerya'da büyük miktarda gerçekleşen petrol keşfinden sonra, kişi başına gelirdeki büyüme oranının sıfır olduğu ve günlük bir doların altında gelirle yaşayan nüfusun toplam nüfus içindeki payının \%36'dan \%70'e yükseldiğini belirtmiştir.

\subsection{Doğal Kaynak Talihsizliği ve Kurumsal Ya- piların Etkileri}

Doğal kaynak talihsizliğinin açıklamalarından biri de kötü kurumsallaşma ve yönetişim göstergeleridir. Bu kapsamda dolaylı etkilere sahip siyasi rejimlere, demokrasi ve insan haklarına, yolsuzluk ve yozlaşma ile birlikte iç savaşlara kadar giden huzursuzluklara dikkat çekilmektedir. Leite ve Weidman (1999), doğal kaynaklardan gıda ve tarımsal ham maddelerin aksine, yakıt ve yakıt dışı minerallerin yolsuzluğu teşvik ettiği bulgularına ulaşmışlardır. Wantchekon (1999) ve Ross (2001)'un çalışmalarında, petrol üretimine olan bağımlıık ile otoriter rejimler arasında pozitif bir ilişki olduğu belirlenmiştir. 1950-1990 dönemi için 141 ülkeyi inceleyen Wantchekon (1999), birincil ürün ihracatının GSYH içindeki payıyla ölçülen doğal kaynak bağımlılığındaki \%1 oranda bir artışın, otoriter yönetim olasılığını yaklaşık \%8 artırdığını ve kaynak zengini ülkelerin demokrasiye geçişte başarısız deneyimler yaşadıklarını ifade etmiştir. Ross (2001) ise, petrol ve mineral zenginliğinin daha az demokratik rejimlere neden olduğu sonucuna ulaşmıştır. Burada- ki mekanizma iki önemli kanal aracılığıyla gelişmektedir. Birincisi, petrol gelirlerinin düşük vergilendirme ve rejimi koruyucu harcamalar yoluyla otoriter rejimleri sürdürmek için kullanıldığını ifade eden 'rantçı devlet etkisi' dir. İkincisi ise, petrol zengini ülkelerdeki otoriter rejimlerin, petrol gelirlerini yoğun bir şekilde savunma ve güvenlik harcamaları için kullanarak iktidarda kalmayı amaçladıklarını ifade eden 'baskı etkisi' dir. Bu kapsamda doğal kaynak zenginliği sadece daha düşük büyümeye neden olmakla kalmamakta, aynı zamanda demokrasinin ve bireysel özgürlüklerin gelişmesini de engellemektedir.

Acemoglu vd. (2001), kurumsal niteliğin bir ölçümü olarak yatırımcılar için kamulaştırma riskini kullanırlarken, Acemoglu vd. (2003) ise ülke yönetimi üzerindeki kısıtlamaları almışlardır. Bu çalışmalarda, zayıf kurumsallaşmanın eşitsizliğe ve bazen diktatörlüklere neden olduğu ve ülkede yolsuzluğu ve yağmacılığı teşvik ettiği belirtilmiştir.

Hausmann ve Rigoban (2003), kaynak gelirleri üzerindeki ortak kullanım probleminin ya da mülkiyet haklarıyla ilgili belirsizliklerin, mevcut kaynaklar üzerinde daha düşük ekonomik büyümeye neden olabilen verimsiz mücadelelere neden olabileceğini öne sürmüşlerdir.

Zengin doğal kaynaklara sahip olan bir ülke için iktidarda kalmanın önemi de daha fazla olmaktadır. Bu durum kaynakların dağııımı için kullanılan siyasi teşvikleri ve siyasi kayırmacılığı (partizanlık) güçlendirmektedir. Gerring ve Thacker (2004), herhangi bir ülkenin bölgesel yönetiminin üniter ya da federal oluşunun ve yürütme organının parlamenter ya da başkanlık sistemi oluşunun siyasi yolsuzluk üzerindeki etkisini araştırmışlardır. Araştırma sonucunda, parlamenter hükümetin yolsuzluğu azaltmada daha etkin olduğunu destekler bulgular elde etmişlerdir. Jensen ve Wantchekon (2004), Afrika bölgesindeki kaynak zengini ülkelerdeki yönetimin daha otoriter olduğunu ve söz konusu ülkelerin demokrasiye geçtikten sonra da rejimde kırımalar yaşadıklarını belirtmişlerdir. Kunicova ve Rose-Ackerman (2005), nispi temsil sisteminin çoğunlukçu sisteme göre rant kollamayı ve yolsuzluğu daha fazla teşvik ettiği ve nispi temsil sisteminin başkanlık sistemiyle birleştiğinde rant kollama faaliyetlerinin daha da arttığı sonucuna ulaşmışlardır. 
Bulte vd. (2005), doğal kaynak zenginliği ve refah arasındaki ilişkiyi araştırdıkları çalışmada, kaynak zengini ülkelerin nispeten daha düşük insani gelişim seviyesine sahip olduklarını belirlemişlerdir. Doğal kaynak donanımı ve refah arasındaki pozitif ilişkiyi destekleyecek sağlam kanıtlar bulmamalarına rağmen, kurumsal gelişme ile bu ilişkinin güçleneceğini ortaya koymuşlardır. Robinson vd. (2006), doğal kaynak zengini ülkelerdeki politikacıların, gelecekteki neslin ihtiyaçlarını önemsemeyerek aşırı kaynak çıkarımını teşvik ettiklerini ifade etmişlerdir. Kaynak gelirlerindeki ani artışlar, iktidarda olmanın önemini artırdığı ve siyasetçilere seçim sonuçlarını etkilemekte kullanabilecekleri kaynaklar yarattığı için, kaynak gelirlerinin ekonominin geri kalanına yanlış bir şekilde dağılımının söz konusu olduğunu belirtmişlerdir. Mehlum vd. (2006a, 2006b), kaynak zengini ülkelerin büyüme performanslarındaki değişkenliğin başlıca nedeni olarak, kaynak gelirlerinin kurumsal düzenlemeler yoluyla nasıl dağıtılığı üzerinde durmuşlardır. Buna göre, kaynak talihsizliğinin başkanlık sistemiyle yönetilen demokratik ülkelerde var olduğu, ancak parlamenter sistemle yönetilen demokratik ülkelerde geçerli olmadığı ifade edilmektedir. Ayrıca çoğunlukçu seçim sisteminin geçerli olduğu ülkelerde kaynak zenginliğinin büyümeye olan olumsuz etkisinin daha az olduğu belirtilmiştir. Petermann vd. (2007), yakıt ihracatındaki artışın genel olarak yolsuzluğu ve yakıt dışı mineral ihracatının ise, özellikle elmas ve altın gibi değerli madenleri ihraç eden düşük gelirli ülkelerde, yolsuzluğu artırdığını göstermişlerdir. Ayrıca kişi başına gelirdeki artışla ifade edilen ekonomik büyümenin ilk aşamalarında yolsuzluğun artma eğiliminde olduğu, ancak daha sonraki evrelerde azaldığını belirtmişlerdir. Pessoa (2008), kaynak zenginliği ve büyüme arasındaki negatif ilişkide kötü kurumsal yapıların olumsuz etkileri olduğunu ifade ederken, ayrıca iyi kurumların büyümeyi artırabileceğini belirtmiştir. Kolstad ve Soreide (2009), kaynak zengini ülkelerin kötü bir ekonomik performans sergilemelerinin temel nedeni olarak yolsuzluğu göstermiş ve kaynak zengini ülkelerdeki yolsuzluğun rant kollama ve kayırmacılık olarak iki şekilde ortaya çıktığını ifade etmişlerdir. Elde edilen rantların bir sonucu olarak bireyler, zaman ve becerilerini daha verimli bir şekilde kullanmak yerine, bu gelirlerden en büyük payı alabilme yarışı içine girmektedirler. Hükümetler iktidarda kalabilmek için destekçilerine kayırmacılık (nepotizm, kronizm) yapabilmektedir. Bu durumun bir sonucu olarak da kamu gelirleri yanlış bir şekilde tahsis edilmekte ve hesap verebilirlik azalmaktadır. Busse ve Gröning (2011), doğal kaynak ihracatının yolsuzluğu artırdığı yönünde bulgular elde etmelerine rağmen, diğer yönetişim göstergeleriyle ilgili kesin sonuçlar elde etmemişlerdir. Metcalf ve Wolfram (2010), siyasi şeffaflık ve petrol üretimindeki değişkenlik arasında belirgin bir şekilde negatif ilişki bulmuşlardır. Ayrıca değişkenliğin otoriter rejimlerde demokratik rejimlere göre daha fazla olduğu ve petrol zengini ülkelerde otoriter rejimlerin genellikle daha uzun süre iktidarda kaldıkları görülmektedir. Yang (2010), kaynak zenginliğinin olumsuz etkilerini yok etme konusunda kurumsal niteliğin önemli bir rol oynayabileceğini vurgulamıştır. Williams (2011), nispeten yeni bir şeffaflık endeksini ve panel verileri kullanarak, doğal kaynak ihracatı gelirlerinden şeffaflığa doğru güçlü bir negatif nedenselliğin olduğunu tespit etmiştir. Yazar, ayrıca şeffaflıktan uzaklaşmanın ekonomik büyümeyi azaltacağını ortaya koymuştur.

Gittikçe sayıları artan bu çalışmalara rağmen, doğal kaynak zenginliği ile ekonomik büyüme arasındaki doğrudan ilişkilerde, kurumlar temelli yönetişim göstergelerinin aracılık etkisini ele alan çalışmaların sayısı oldukça azdır. Ayrıca mevcut çalışmalarda aracılık etkisinin boyutlarının ve anlamlılığının yeterince ve net olarak ortaya konulmadığı görülmektedir. Literatürdeki bu boşluktan yola çıkarak hazırlanan bu çalışma, farklı bir yöntem ve güncel veri setleriyle, literatürdeki bu eksikliğe bir katkı sağlamayı amaçlamaktadır.

\section{AMPIRIK ÇERÇEVE}

Çalışmanın ampirik bölümünde önce tahmin edilecek modeller tanıtılmakta ve veri setleri ile kaynakları açıklanmaktadır. Sonrasında, farklı testler yardımılla belirlenen uygun tahminciler ile yapılan ikili ve hiyerarşik panel regresyon analiz sonuçları sunulmaktadır.

\subsection{Geleneksel Aracılık Etkisi Modeli}

Kaynak talihsizliği literatüründe yaygın olarak ayrı ayrı incelenen ve yukarıda özet olarak sunulan farkIı yönetişim göstergelerinin dolaylı etkileri, Baron ve Kenny (1986)'nin klasik aracılık ilişkisi yaklaşımından yola çıkarak şu şekilde modellenmiştir:

$$
\begin{aligned}
& {\left[\begin{array}{c}
\text { M: Araci Degisken } \\
\text { (Küresel Yönetisim Göstergeleri) }
\end{array}\right]} \\
& \uparrow(-) \quad \downarrow(+) \\
& \uparrow \quad \downarrow \\
& {\left[\begin{array}{l}
\text { X: Bagimsiz Degisken } \\
(\text { Dogal Kaynak Zenginligi })
\end{array}\right] \Rightarrow \underset{(-)}{\stackrel{(+)}{\Rightarrow}} \Rightarrow\left[\begin{array}{l}
\text { Y: Bagimli Degisken } \\
(\text { Ekonomik Büyüme })
\end{array}\right]} \\
& \Rightarrow \text { :Dogrudan etki; } \rightarrow \text { :Dolayli etki }
\end{aligned}
$$

Bu genel modelde, bağımsız değişken olan doğal kaynak zenginliği, kişi başına ham petrol üretimi ile ve bağımlı değişken olan ekonomik büyüme performansı ise kişi başına reel GSYH ile temsil edilmiştir. Modelde bu iki değişken arasındaki ilişkide kurumsal yönetişim göstergelerinin aracılık etkisini daha net görebilmek için, büyümeyi etkileyen diğer değişkenler model dışında tutulmuştur. Buna göre daha ön- 
ceki çalışmaların ampirik bulgularından yola çıkarak doğal kaynak zenginliğinin küresel yönetişim gösterilerini olumsuz etkilemesi beklenmektedir. Küresel yönetişim göstergelerinin gelişmesinin ise ekonomik büyümeyi artırması beklenmektedir. Böylece, doğal kaynak zenginliğinin ekonomik büyümeyi net olarak artırması ya da azaltması, aracı değişken olan yönetişim göstergelerinin dolaylı etkilerine bağlı olmaktadir.

Bir değişkenin aracı değişken olabilmesi için dört temel özelliği taşıması gerekmektedir (Baron ve Kenny, 1986): i) Öncelikle bağımsız değişken, aracı etkisi beklenen değişkeni anlamlı bir biçimde etkilemelidir. ii) Aracı etkisi beklenen değişken, bağımlı değişkeni anlamlı bir biçimde etkilemelidir. iii) Bağımsız değişken, bağımlı değişeni doğrudan anlamlı bir biçimde etkilemelidir. iv) Dördüncü ve son koşul olarak aracı değişken bağımsız değişken ile birlikte tahmin edilen regresyon modeline dahil edildiğinde, bağımsız değiş̧kenin bağımlı değişken üzerindeki etkisi azalmalı ya da tamamen ortadan kalkmalıdır. İlişki tamamen ortadan kalkarsa 'tam aracılık etkisi', ilişkinin azalması durumunda ise 'kısmi aracılık etkisi' ortaya çıkmaktadır. Baron ve Kenny (1986)'nin bu yöntemi özellikle bir potansiyel aracı değişkenin olması durumunda daha etkin sonuçlar ortaya koymaktadır. Bu kapsamda çalışmanın sonuçları yorumlanırken, doğal kaynak zenginliği ile büyüme arasındaki ilişkiyi etkileyen başka faktörlerin olduğu ve büyümenin diğer belirleyicilerin modele alınmadığı göz ardı edilmemelidir. Baron and Kenny (1986)'nin klasik aracılık etkisi testine göre çalışmada tahmin edilecek dört regresyon modeli aşamalı olarak şu şekilde oluşturulmuştur.

$$
\begin{aligned}
& W G I=\beta_{1}+a C O P P C+\varepsilon_{1} \\
& G D P P C=\beta_{2}+b W G I+\varepsilon_{2} \\
& G D P P C=\beta_{3}+c C O P P C+\varepsilon_{3} \\
& G D P P C=\beta_{4}+c^{\prime} C O P P C+b^{\prime} W G I+\varepsilon_{4}
\end{aligned}
$$

Burada aracı değişken olan WGI küresel yönetişim göstergelerini; bağımsız değişken olan COPPC kişi başına ham petrol üretimini ve bağımlı değişken olan GDPPC kişi başına reel GSYH miktarını göstermektedir. $\beta$ simgeleri regresyon sabitlerini ve $\varepsilon$ simgeleri model uyum hatalarını gösterirken $a, b, c$ ile $b^{\prime}$ ve $c^{\prime}$ ise ele alınan üç değişken arasındaki regresyon katsayılarıdır. Buna göre, GDPPC bağımlı değişkeni ile COPPC bağımsız değişkeni arasındaki ilişkide WGI değiş̧keninin aracılık etkisinin olması için denklem (1), (2) ve (3)'te $a, b$, ve $c$ katsayıları anlamlı olmalı ve denklem (4)'teki model tahmininde $c^{\prime}$ katsayısı azalmalı (kısmı aracılık etkisi) ya da tamamen ortadan kalkmalıdır (tam aracılık etkisi). Çalışmanın analiz prosedüründe bu dört denklem sırasıyla ve uygun tahmincilerle test edilmektedir. Bir aracılık etkisinin bulunması duru- munda, bu etkinin istatistiki olarak anlamlılığı Sobel (1982) testi aracılığıyla doğrulanmaktadır. Buna göre denklem (3)'teki c nin büyüklüğü ile denklem (4)'teki $c^{\prime}$ nün büyüklüğü z-testi ile şu şekilde karşılaştırılmaktadır:

$$
z=\frac{a \cdot b}{\sqrt{b^{2} s_{a}^{2}+a^{2} s_{b}^{2}}}
$$

Burada, $a$ bağımsız değişken ile aracı değişken arasındaki standartlaştırımamış (ham) regresyon katsayılarını, $s_{a}$ ise $a$ nın standart hatasını (denklem 1) göstermektedir. Yine $b$, bağımsız değişkenin de bağımlı değişkenin bir tahmincisi olarak modele alınması durumunda, aracı ve bağımsız değişken arasındaki standartlaştırılmamış regresyon katsayısını (denklem 4) ve $s_{b}$ ise $b$ nin standart hatasını göstermektedir. Elde edilen $z$ değeri $\% 5$ anlam düzeyinde kritik değerden $(+/-1,96)$ büyük (küçük) ise aracılık etkisinin anlamsız (anlamlı) olduğu belirlenmektedir.

\subsection{Veri Seti ve Veri Kaynakları}

Çalışmada, küresel yönetişim göstergeleri (WGI) verilerinin varlığına bağlı olarak, 1996-2012 dönemini kapsayan 17 ( $T$ ) yıllık dengeli panel veriler kullanılmıştır. Dizi genişliğinin yüksek olması amacıyla, değişkenler bakımından heterojen bir yapıda 16 MENA ülkesi (B.A.E, Bahreyn, Cezayir, Fas, Irak, İsrail, Katar, Kuveyt, Libya, Mısır, Suriye, Suudi Arabistan, Tunus, Türkiye, Umman ve Yemen) ve 5 Hazar denizi ülkesi (Azerbaycan, İran, Kazakistan, Rusya ve Türkmenistan) olmak üzere toplam $21(N)$ ülkeli panel veri setleri kullanılmıştır.

Panel veri setleri geleneksel yatay-kesit ve zaman serilerine kıyasla bazı avantajlar sağlamaktadır: Panel veri setlerinde, yatay-kesit ve zaman serisi gözlemleri birleştirildiğinden gözlem sayısı daha fazla olmakta, serbestlik derecesi artmakta ve açıklayıcı değişkenler arasında çoklu bağlantı sorunu nispeten azalmaktadır. Kısa zaman serisi ve/veya yetersiz kesit gözleminin var olduğu durumlarda da analiz yapılmasını mümkün hale getiren panel veri analizi, değişkenlere ilişkin heterojenliklere de olanak vererek ekonometrik tahminlerin etkinliğini artırmaktadır (bkz. Hsiao, 2003: 1-8; Baltagi, 2005: 4-9).

Ülkelerin yönetişim ve kurumsal yapılarına ilişkin veriler, Dünya Bankası'nın Küresel Yönetişim Göstergeleri (WB-WGI, 2014) veri tabanından alınmıştır. Bu göstergeler, altı temel kategoride ve çok sayıda alt gösterge üzerinden hesaplanmaktadır: i) Ifade özgürlüğü ve hesap verebilirlik (siyasette askeri unsurların varlığı ve demokratik hesap verebilirlik), ii) siyasi istikrar ve huzur (şiddet olaylarının olmaması, hükümet istikrarı, yurtiçi anlaşmazlıklar, yurtdışı anlaşmazlıklar, etnik ve dini problemler), iii) hükümetin etkinliği (bürokratik 
kalite), iv) düzenleme kalitesi (yatırım ortamı), v) hukukun üstünlüğü ve vi) yolsuzluğun kontrolü. Buna göre yönetişim göstergeleri, kanun ve diğer yazılı hükümet yaptırımlarının yanında, ahlak anlayışlarını, gelenek-görenekleri ve kurumsal yapıları da içine alan geniş kapsamlı bir yapıda ele alınmaktadır. Dünya Bankası'nın 1996-2012 dönemi için mevcut olan kü- resel yönetişim verileri, 1996-2002 döneminde birer yıl arayla, sonrasında ise yıllık olarak sunulmaktadır. Panel verileri dengeli hale getirmek için, 1997, 1999 ve 2001 yıllarının eksik verileri, önceki ve sonrası yılların basit ortalaması alınarak elde edilmiştir. Çalışmada kullanılan tüm değişkenlere ilişkin bilgiler aşağıda Tablo 2'de özetlenmiștir.

Tablo 2: Kullanılan Değişkenler, Açıklamaları ve Veri Kaynakları

\begin{tabular}{|c|c|c|c|}
\hline Zaman Serisi & Değişken & Açıklama & Kaynak \\
\hline Ek. Büyüme & GDPPC & Kişi Başına Reel GSYH, TÜFE Bazlı, (Log) & WB-WDI \\
\hline $\begin{array}{c}\text { Ortalama Küresel } \\
\text { Yönetişim } \\
\text { Göstergeleri }\end{array}$ & AWGI & $\begin{array}{l}\text { Altı Küresel Yönetişim Göstergesi Ortalaması } \\
\text { (i. İfade özgürlüğü ve hesap verebilirlik, ii. Şiddet/terör bakımından } \\
\text { huzur ve politik istikrar, iii. Hükümet etkinliği, iv. Düzenleme } \\
\text { kalitesi, v. Hukuk düzeni/hukukun üstünlüğü, vi. Yolsuzluk kontrolü). } \\
-2,5<A W G I<2,5 \text {; } \\
\qquad(+2,5 \text { ile pozitife dönüştürülmüştür: } 0<A W G \mid<5 \text { (Log) }\end{array}$ & WB-WGI \\
\hline $\begin{array}{c}\text { Doğal Kaynak } \\
\text { Zenginliği }\end{array}$ & COPPC & Kişi başına ham petrol üretimi, varil, (Log) & US-EIA \\
\hline $\begin{array}{l}\text { Modifikasyon } \\
\text { verileri }\end{array}$ & & TÜFE, Nüfus & WB-WDI \\
\hline
\end{tabular}

\subsection{Panel Veri Analiz Süreci ve Ampirik Bulgular}

Panel regresyon analizinden önce panel birim kök testleri ile serilerin durağanlıklarının test edilmesi gerekmektedir. Durağanlık testlerinde, zaman $(T)$ ve yatay kesit $(N)$ boyutunun karşılaştırmalı büyüklüğüne göre farklı testler uygulanabilmektedir. Çalışmada, boyut özelliklerine $(N>T ; 21>17)$ uygun olarak önce Pesaran (2004) $C D_{L M}$ testi uygulanmış ve $A W G$ serisinin durağan olmadığı belirlenmiştir ${ }^{(1)}$. Ancak, merkezi limit teoremi'nden hareketle, bu çalışmada olduğu gibi, panel verilerin zaman kesiti $(T=17)$ sınırlı oldu- ğunda, birim kök testlerinin güvenilirlikleri azalmaktadır (bkz. Hsiao, 2003: 298-301; Baltagi, 2005: 237250). Sonrasında, seri özelliklerinin görülebilmesi için, genel (ortak) birim kök sürecini dikkate alan Levin, Lin ve Chu (2002) panel birim kök testi uygulanmış, sonuçlar Tablo 3'te sunulmuştur. Sonuçlar, hiyerarşik regresyon analizinde kullanılan üç temel değişkenin seviyede durağan $(I(0))$ olduğunu göstermektedir. Ancak, yine regresyon katsayıları yorumlanırken, zaman boyutunun kısa olduğu ve alt göstergelerde bazı serilerin durağan olmadığı göz ardı edilmemelidir.

Tablo 3: Panel Birim Kök Test Sonuçları

\begin{tabular}{|c|c|c|c|c|}
\hline \multirow[t]{2}{*}{ Değişken } & \multicolumn{2}{|c|}{ Trendsiz } & \multicolumn{2}{|c|}{ Trendli } \\
\hline & Test ist. & $p$ & Test ist. & $p$ \\
\hline GDPPC & $-2,101 *$ & 0,017 & $-1,891 *$ & 0,029 \\
\hline COPPC & $-3,165^{* *}$ & 0,000 & $-1,971^{*}$ & 0,024 \\
\hline \multicolumn{2}{|c|}{$\begin{array}{c}\text { AWGI } \\
-1,767^{*}\end{array}$} & 0,038 & $-2,823 * *$ & 0,000 \\
\hline WGI-I: Ifade özgürlüğü ve hesap verebilirlik & $-2,041^{*}$ & 0,021 & $-0,225$ & 0,411 \\
\hline WGI-II: Huzur ve politik istikrar & 1,315 & 0,906 & $-0,991$ & 0,839 \\
\hline WGI-III: Hükümetin etkinliği & $-0,317$ & 0,364 & $-3,042 * *$ & 0,001 \\
\hline WGI-IV: Düzenleme kalitesi & $-2,366^{* *}$ & 0,009 & 0,274 & 0,608 \\
\hline WGI-V: Hukuk düzeni/hukukun üstünlüğü & $-1,745^{*}$ & 0,041 & $-3,246^{* *}$ & 0,000 \\
\hline WGI-VI: Yolsuzluğun kontrolü & $-2,173^{*}$ & 0,015 & $-2,490^{* *}$ & 0,006 \\
\hline
\end{tabular}

(Not: * ve ** sırasıyla \%5 ve \%1 anlam düzeyinde serilerin durağan olduğunu göstermektedir.) 
Doğrusal panel veri regresyon modelleri genel olarak şu şekilde gösterilebilmektedir:

$Y_{i t}=\beta_{0 i t}+\beta_{1 i t} X_{1 i t}+\beta_{2 i t} X_{2 i t}+\ldots . .+\beta_{k i t} X_{k i t}+u_{i t}$

Çalışmaya uygun olarak denklemde $\mathrm{i}=1,2, \ldots, 21=\mathrm{N}$ olacak biçimde yatay kesit birimlerini, yani ülkeleri ve $t=1996,1997, \ldots, 2012=T$ ise zaman boyutu birimlerini gösterirken; $\mathrm{k}$ açıklayıcı değişken sayısı ve $\mathrm{u}_{\text {it }}$ hata terimidir. Panel verilere ilişkin bütün gözlemlerin homojen olması varsayımının (klasik model) geçerli olmadığı durumda, denklem (6)'da gösterilen genel model tahmin edilmeden önce sabit etkili ya da tesadüfü (rassal) etkili model özellikleri araştırılmaktadır. Bunun için parametrelerin birim ve/veya zamana göre farklı değerler alıp almadığı kontrol edilmektedir. Sabit etkiler modelinde, $N$ sayıdaki yatay kesit için $N$ sayıdaki sabit etki ile açıklayıcı değişkenler arasında korelasyon bulunmaktadır (Hsiao, 2003: 27-33; Baltagi, 2005:12-14). Buna göre sabit etkili modelde,

$\beta_{0 i t}=\beta_{0 i}=\bar{\beta}+\mu_{i} ; \quad \beta_{1 i t}=\beta_{1} ; \quad \beta_{2 i t}=\beta_{2}, \ldots . ., \beta_{k i t}=\beta_{k}$

olduğu varsayılmaktadır. Yani, eğim parametreleri tüm yatay kesit birimler için aynı $\left(\beta_{i}=\beta\right)$ iken, sabit parametre birim etki içerdiğinden birimler arasında değişmektedir.

Örnekleme sürecine bağlı olarak biçimlenen tesadüfi etkiler modelinde ise, örnekteki birimlerin tesadüfi olarak seçilmesi durumunda birimler arası farklılıkların da tesadüfi olması söz konusudur. Buna göre tesadüfi etkiler modelinde hata terimleri iki bileşene ayrılmaktadır: i) Dönemler arası değişmeyen ve yatay kesit etkilerini gösteren tesadüfi etkiler $\left(\mu_{i}\right)$ ve ii) dönemler ve yatay kesitler üzerinde birbirlerinden bağımsız ve özdeş olarak dağılan artık hata terimleri $\left(v_{i t}\right)$ (Hsiao, 2003: 34, 41-49; Baltagi, 2005:14-18). Buna göre (6) numaralı denklem, tesadüfü etkiler modeli kapsamında şu şekilde gösterilebilecektir:

$Y_{i t}=\beta_{0 i t}+\beta_{1 i t} X_{1 i t}+\beta_{2 i t} X_{2 i t}+\ldots . .+\beta_{k i t} X_{k i t}+\left(\mu_{i}+v_{i t}\right)$

Burada, i yatay kesit biriminin sabiti olmak üzere, $\mu_{i}$ birim hatayı, yani yatay kesit tesadüfi etkileri ve $v_{\text {it }}$ tüm model için artık hata terimlerini göstermektedir. Dolayısıyla $\left(\mu_{i}+v_{i t}\right)$ bileşik hata terimini ifade etmektedir. Çalışmada, sabit etkili ya da tesadüfü etkili modellerinden hangisinin kullanılacağına, farklı test (bkz. Hsiao, 2003; Baltagi, 2005) sonuçlarına göre karar verilerek analiz süreci sürdürülmüştür.

Çalışmada ilk olarak yukarıda denklem (1)'de belirtildiği üzere COPPC değişkeninin altı kurumsal gösterge ve bu göstergelerin basit ortalamaları alınarak elde edilen $A W G I$ değişkenine olan etkilerini belirlemek üzere ikili panel regresyon analizi yapılmıştır.

Regresyon analizinde kullanılacak tahmincinin belirlenmesine yönelik yapılan testlerin sonuçları Tablo 4'te görülmektedir.

Tablo 4: Doğal Kaynak Zenginliğinin Ortalama Kurumsal Yönetişim Göstergelerine Etkisinin Belirlenmesinde Kullanılacak Panel Regresyon Tahminci Testleri

\begin{tabular}{|c|c|c|c|c|c|c|c|}
\hline $\begin{array}{l}\text { Bağımlı } \\
\text { Değ. }\end{array}$ & F_grup & F_zaman & $\begin{array}{l}\text { F_çift } \\
\text { yönlü }\end{array}$ & Honda_grup & Honda_zaman & $\begin{array}{c}\text { Honda_çift } \\
\text { yönlü }\end{array}$ & Hausman \\
\hline AWGI & $\begin{array}{l}306,65 \\
(0,000)\end{array}$ & $\begin{array}{c}1,130 \\
(0,325)\end{array}$ & $\begin{array}{l}170,94 \\
(0,000)\end{array}$ & $\begin{array}{c}50,0397 \\
(0,000)\end{array}$ & $\begin{array}{l}-2,784 \\
(0,997)\end{array}$ & $\begin{array}{l}33,414 \\
(0,000)\end{array}$ & $\begin{array}{l}10,920 \\
(0,000)\end{array}$ \\
\hline WGI-I & $\begin{array}{l}70,905 \\
(0,000)\end{array}$ & $\begin{array}{c}3,356 \\
(0,000)\end{array}$ & $\begin{array}{l}40,978 \\
(0,000)\end{array}$ & $\begin{array}{l}41,506 \\
(0,000)\end{array}$ & $\begin{array}{l}-0,990 \\
(0,839)\end{array}$ & $\begin{array}{l}28,649 \\
(0,000)\end{array}$ & $\begin{array}{c}2,278 \\
(0,131)\end{array}$ \\
\hline WGI-II & $\begin{array}{l}15,118 \\
(0,000)\end{array}$ & $\begin{array}{c}0,834 \\
(0,645)\end{array}$ & $\begin{array}{c}8,886 \\
(0,000)\end{array}$ & $\begin{array}{l}21,797 \\
(0,000)\end{array}$ & $\begin{array}{l}-1,265 \\
(0,897)\end{array}$ & $\begin{array}{l}14,518 \\
(0,000)\end{array}$ & $\begin{array}{l}20,800 \\
(0,000)\end{array}$ \\
\hline WGI-III & $\begin{array}{l}219,52 \\
(0,000) \\
\end{array}$ & $\begin{array}{c}1,816 \\
(0,028) \\
\end{array}$ & $\begin{array}{l}122,55 \\
(0,000) \\
\end{array}$ & $\begin{array}{l}49,001 \\
(0,000) \\
\end{array}$ & $\begin{array}{l}-2,701 \\
(0,996) \\
\end{array}$ & $\begin{array}{l}32,738 \\
(0,000) \\
\end{array}$ & $\begin{array}{c}6,024 \\
(0,141) \\
\end{array}$ \\
\hline WGI-IV & $\begin{array}{l}153,63 \\
(0,000) \\
\end{array}$ & $\begin{array}{c}2,610 \\
(0,000)\end{array}$ & $\begin{array}{l}86,420 \\
(0,000) \\
\end{array}$ & $\begin{array}{l}47,429 \\
(0,000) \\
\end{array}$ & $\begin{array}{l}-2,285 \\
(0,998)\end{array}$ & $\begin{array}{l}31,921 \\
(0,000)\end{array}$ & $\begin{array}{c}0,841 \\
(0,359) \\
\end{array}$ \\
\hline WGI-V & $\begin{array}{l}288,45 \\
(0,000)\end{array}$ & $\begin{array}{c}0,768 \\
(0,721)\end{array}$ & $\begin{array}{l}160,55 \\
(0,000)\end{array}$ & $\begin{array}{l}50,115 \\
(0,000)\end{array}$ & $\begin{array}{l}-2,876 \\
(0,997)\end{array}$ & $\begin{array}{l}33,402 \\
(0,000)\end{array}$ & $\begin{array}{c}5,881 \\
(0,015)\end{array}$ \\
\hline WGI-VI & $\begin{array}{l}145,70 \\
(0,000)\end{array}$ & $\begin{array}{c}1,527 \\
(0,088)\end{array}$ & $\begin{array}{l}81,658 \\
(0,000)\end{array}$ & $\begin{array}{l}47,426 \\
(0,000)\end{array}$ & $\begin{array}{l}-2,494 \\
(0,993)\end{array}$ & $\begin{array}{l}31,771 \\
(0,000)\end{array}$ & $\begin{array}{c}0,641 \\
(0,423)\end{array}$ \\
\hline
\end{tabular}

(Not: Parantez içerisindeki değerler, test istatistiklerinin olasılık ( $p$ ) değerlerini göstermektedir.) 
Regresyon analizinde kullanılacak tahmincinin belirlenmesine yönelik yapılan testlerden $F$ testi sonuçları, sabit etkiler tahmincisi ile havuzlanmış EKK (pooled OLS) tahmincisini karşılaştırırken, Honda testi ise rassal etkiler ve havuzlanmış EKK tahmincilerini karşılaştırmaktadır. Bu testlerden sabit etkiler ve rassal etkiler tahmincilerinin her ikisinin de kullanılabileceği yönünde bir sonuç elde edilmesi durumunda ise, Hausman testi sonucuna göre hangi tahmincinin kullanılacağına karar verilmektedir (bkz. Hsiao, 2003; Baltagi, 2005). Yapılan test sonuçlarından doğal kaynak zenginliği ile $A W G I, W G I-I l$ ve $W G I-V$ değişkenlerinin regresyonunda tek yönlü sabit etkiler tahmincisinin; WGI-III, WGI-IV ve WGI-VI değişkenlerinin regresyonunda tek yönlü rassal etkiler tahmincisinin ve WGI-I regresyonunda ise çift yönlü rassal etkiler tahmincisinin kullanılacağı anlaşılmaktadır.

Doğrusal regresyon modelinin iki önemli varsayı$\mathrm{ml}$, hata teriminin sabit varyansa sahip olması ve hata terimleri arasında ilişki olmamasıdır (Hsiao, 2003; Baltagi, 2005). Tablo 4'teki sonuçlara bağlı olarak, belirlenen uygun regresyon modellerine ilişkin değişen varyans ve otokorelasyon test sonuçları Tablo 5'de gösterilmiştir.

Tablo 5: Değişen Varyans ve Otokorelasyon Testleri

\begin{tabular}{|c|c|c|c|c|c|c|c|}
\hline Bağımsız değ. (COPPC) & AWGI & WGI-I & WGI-II & WGI-III & WGI-IV & WGI-V & WGI-VI \\
\hline $\begin{array}{c}\text { Değişen Varyans } \\
\text { (LMh) }\end{array}$ & $\begin{array}{l}203,38 \\
(0,000)\end{array}$ & $\begin{array}{l}309,18 \\
(0,000)\end{array}$ & $\begin{array}{c}1471,16 \\
(0,000)\end{array}$ & $\begin{array}{c}367,058 \\
(0,000)\end{array}$ & $\begin{array}{l}399,12 \\
(0,000)\end{array}$ & $\begin{array}{l}270,80 \\
(0,000)\end{array}$ & $\begin{array}{l}130,89 \\
(0,000)\end{array}$ \\
\hline $\begin{array}{l}\text { Otokorelasyon } \\
\left(L M_{\text {_stat }} / M_{\mu \rho}\right)\end{array}$ & $\begin{array}{l}176,98 \\
(0,000)\end{array}$ & $\begin{array}{c}1722,85 \\
(0,000)\end{array}$ & $\begin{array}{l}118,91 \\
(0,000)\end{array}$ & $\begin{array}{c}2226,26 \\
(0,000)\end{array}$ & $\begin{array}{c}2250,42 \\
(0,000)\end{array}$ & $\begin{array}{l}205,02 \\
(0,000)\end{array}$ & $\begin{array}{c}2074,44 \\
0,000)\end{array}$ \\
\hline
\end{tabular}

(Not: Parantez içerisindeki değerler, test istatistiklerinin olasılık $(p)$ değerlerini göstermektedir.)

Tablo 5'te tüm regresyon modellerinde değişen varyans ve otokorelasyon sorunu olduğu anlaşılmaktadır. Regresyon modellerinin, değişen varyans ve otokorelasyon sorunları kapsamında dönem ağırlıkla-

Tablo 6: Doğal Kaynak Zenginliğinin Kurumsal Yönetişim Göstergelerine Etkisi, İkili Panel Regresyon Analizi (Bağımsız Değişken: (OPPC)

\begin{tabular}{|c|c|c|c|c|c|c|}
\hline Bağımlı Değişken & Katsayı & $t$ & $p$ & $F$ & $R 2$ & İlişki ve anlamlılık \\
\hline AWGI & $-0,023$ & $-5,911$ & $0,000 * *$ & 34,935 & 0,089 & (-) anlamlı \\
\hline WGI-I & $-0,037$ & $-2,040$ & $0,042 *$ & 2,908 & 0,008 & (-) anlamlı \\
\hline WGI-II & 0,841 & 4,507 & $0,000^{* *}$ & 15,393 & 0,491 & (+) anlamlı \\
\hline WGI-III & $-0,021$ & $-2,857$ & $0,004^{* *}$ & 8,163 & 0,023 & (-) anlamlı \\
\hline WGI-IV & $-0,028$ & $-3,646$ & $0,000^{* *}$ & 7,455 & 0,020 & (-) anlamlı \\
\hline WGI-V & $-0,011$ & $-0,366$ & 0,714 & 1,961 & 0,005 & (-) anlamsız \\
\hline WGI-VI & $-0,020$ & $-4,663$ & $0,000^{* *}$ & 20,485 & 0,054 & (-) anlamlı \\
\hline
\end{tabular}

(Not: * ve ** sırasıyla regresyon katsayılarının $\% 5$ ve \%1 düzeyinde anlamlı olduğunu göstermektedir.)
Tablo 6'daki sonuçlara göre COPPC değişkeninin altı küresel yönetişim göstergesinin ortalamasından elde edilen AWGI değişkenini anlamlı bir biçimde negatif etkilediği görülmektedir. Alt yönetişim göstergelerinde ise WGI-V (hukuk düzeni/hukukun üstünlüğü) boyutunu negatif etkilemesine rağmen etkinin istatistiki olarak anlamsız olduğu görülmektedir. WGIII (huzur ve politik istikrar) boyutunu anlamlı bir şekilde pozitif etkilemesi, bir anlamda, iktidarların uzun süre yönetimi elde tutma gayretlerine işaret etmektedir. Diğer alt yönetişim göstergeleri için ise, beklendiği üzere, COPPC değişkeni anlamlı bir biçimde negatif etkiye sahiptir. Buna göre ele alınan ülkeler kapsamında doğal kaynak zenginliğinin yönetişim kalitesini bozma eğiliminde olduğu desteklenmektedir.

Denklem (2)'de belirtilen, alt yönetişim gösterge- rını dikkate alan, panel düzeltilmiş standart hata ( $p a-$ nel-corrected standard error-PCSE) yöntemiyle tahmin edilmiş sonuçları aşağıda Tablo 6'da sunulmuştur: leri ve ortalama yönetişim göstergesi ile kişi başına reel GSYH arasındaki regresyonda kullanılan tahminci yine $F$, Honda ve Hausman testleri doğrultusunda belirlenmiştir. Bu test sonuçlarına göre alt yönetişim göstergeleri ve ortalama yönetişim göstergesi ile kişi başına reel GSYH arasındaki regresyonda kullanılacak tahmincinin, hem grup hem de zaman etkisini dikkate alan çift yönlü sabit etkiler tahmincisi olduğu belirlenmiştir(1). Ayrıca yapılan $L M h$ ve $L M \_s t a t / L M_{\mu \rho}$ testleri sonucu bu regresyon modellerinin tamamında yine değiş̧en varyans ve otokorelasyon sorunları olduğu görülmüştür(1). Buna bağlı olarak, bu regresyon modelleri de, çift yönlü sabit etkiler tahmincisi ile değişen varyans ve otokorelasyonu da dikkate alarak (PCSE ile) benzer şekilde tahmin edilmiş ve sonuçlar Tablo 7'de sunulmuştur. 
Tablo 7: Küresel Yönetişim Göstergelerin Kişi Başına Reel GSYH'ya Etkisi, İkili Panel Regresyon Analizi (Bağımlı değişken: GDPPC)

\begin{tabular}{|c|c|c|c|c|c|c|}
\hline Bağımsız değişken & Katsayı & $t$ & $p$ & $F$ & $R^{2}$ & İlişki ve anlamlılık \\
\hline AWGI & 2,542 & 4,660 & $0,000 * *$ & 21,243 & 0,516 & (+) anlamlı \\
\hline WGI-I & 1,074 & 7,443 & $0,000^{* *}$ & 3,454 & 0,148 & (+) anlamlı \\
\hline WGI-II & 0,370 & 7,150 & $0,000^{* *}$ & 3,098 & 0,134 & (+) anlamlı \\
\hline WGI-III & 2,078 & 15,540 & $0,000^{* *}$ & 14,848 & 0,427 & (+) anlamlı \\
\hline WGI-IV & 1,218 & 11,425 & $0,000^{* *}$ & 8,183 & 0,291 & (+) anlamlı \\
\hline WGI-V & 0,560 & 5,717 & $0,000^{* *}$ & 498,68 & 0,983 & (+) anlamlı \\
\hline WGI-VI & 2,542 & 19,996 & $0,000 * *$ & 23,176 & 0,537 & (+) anlamlı \\
\hline
\end{tabular}

(Not: * ve ** sırasıyla regresyon katsayılarının \%5 ve \%1 düzeyinde anlamlı olduğunu göstermektedir.)

Buna göre hem alt boyutlarında hem de genel ortalama bakımından küresel yönetişim göstergelerinin kişi başına reel GSYH'yı anlamlı bir biçimde pozitif etkilediği görülmektedir. Sonuçlar, ele alınan ülkelerde yönetişim kalitesindeki ilerlemelerin, ekonomik büyüme performansını ciddi bir biçimde artıracağına işaret etmektedir.

Doğal kaynak zenginliğinin bir taraftan büyümeyi doğrudan hızlandırması, diğer yandan kurumsal yapıyı bozarak dolaylı bir biçimde büyümeyi engellemesi, yönetişim göstergelerinin aracılık etkisinin belirlenmesinin önemini ortaya koymaktadır. Bu kapsamda son olarak toplulaştırılmış altı küresel yönetişim göstergesinin, doğal kaynak zenginliği ve kişi başına GSYH arasındaki doğrudan ilişkide oynadığı dolaylı aracı değişken rolünün belirlenmesi için hiyerarşik regresyon analizi yapılmış ve sonuçlar Tablo 8'de sunulmuştur.

Denklem (3) kapsamında, doğal kaynak zenginliği ile kişi başına reel GSYH arasındaki regresyonda kullanılan tahminci yine $F$, Honda ve Hausman testleri ile belirlenmiştir. Test sonuçları tek yönlü (grup etkisi) rassal etkiler tahmincisine işaret etmektedir ${ }^{(1)}$. $L M h$ ve $L M_{\_} s t a t / L M_{\mu \rho}$ testleri $^{(1)}$ sonucu tespit edilen değişen varyans ve otokorelasyon sorunlarını dikkate alarak (PCSE ile) yapılan regresyon modeli tahmin sonuçları Tablo 8'in (3) numaralı modelinde sunulmuştur. Sonuçlar doğal kaynak zenginliğinin büyümeyi doğrudan artırıcı bir rol oynadığı yönündedir. Denklem (4) kapsamında son olarak, çift yönlü sabit etkiler tahmincisi ile tahmin edilen (4) numaralı model ile aracılık etkisi test edilmiştir(1).

Tablo 8: Hiyerarşik Regresyon Analizi ve Sobel Testi Sonuçları

\begin{tabular}{|c|c|c|c|c|c|c|c|c|}
\hline \multicolumn{9}{|c|}{ Hiyerarşik Regresyon Analizi Model Tahminleri } \\
\hline Model no. & $\begin{array}{l}\text { Bağımsız } \\
\text { değ. }\end{array}$ & Bağımlı değ. & Katsayı & $t$ & $p$ & $\boldsymbol{F}$ & $R^{2}$ & $\begin{array}{l}\text { İliş̧ki ve } \\
\text { anlamlılık }\end{array}$ \\
\hline 1 & COPPC & $A W G I$ & $-0,023$ & $-5,911$ & $0,000^{* *}$ & 34,935 & 0,089 & (-) anlamlı \\
\hline 2 & AWGI & GDPPC & 2,542 & 4,660 & $0,000^{* *}$ & 21,243 & 0,516 & (+) anlamlı \\
\hline 3 & COPPC & GDPPC & 0,303 & 8,200 & $0,000^{* *}$ & 84,021 & 0,191 & (+) anlamlı \\
\hline 4 & COPPC;AWGI & GDPPC & $\begin{array}{l}0,172 \\
2,649\end{array}$ & $\begin{array}{l}11,903 \\
-6,133\end{array}$ & $\begin{array}{l}0,000^{* * *} \\
0,000^{* *}\end{array}$ & 36,272 & 0,658 & (+) anlamlı \\
\hline \multicolumn{9}{|c|}{ Sobel Testi } \\
\hline \multicolumn{3}{|c|}{ Test ist. (z-değeri) } & \multicolumn{3}{|c|}{ Std. Hata } & $p$ & \multirow{2}{*}{\multicolumn{2}{|c|}{ Kısmi aracılık etkisi anlamlı }} \\
\hline \multicolumn{3}{|c|}{$-5,728$} & \multicolumn{3}{|c|}{0,011} & 0,000 & & \\
\hline
\end{tabular}

(Not: * ve ** sırasıyla regresyon katsayılarının \%5 ve \%1 düzeyinde anlamlı olduğunu göstermektedir.)

Tabloda tahmin edilen (1) numaralı modelde doğal kaynak zenginliğinin yönetişim göstergelerini anlamlı bir biçimde kötüleştirdiği görülmektedir. (2) numaralı modelin tahmin sonuçları ise, kurumsal göstergelerin iyileşmesinin anlamlı bir biçimde kişi başına geliri de artırdığını göstermektedir. (3) numaralı modelde ise, doğal kaynak zenginliğinin ekonomik büyümeyi artırma eğiliminde olduğu görülmektedir. Çift yönlü sabit etkiler tahmincisi ile tahmin edilen (4) numaralı modelde ise, aracı değişkenin de açıklayıcı değişken olarak modelde tahmin edilmesiyle birlikte
(3) numaralı modelde elde edilen katsayının $(0,303)$ azaldığı $(0,172)$ görülmektedir. Buna göre ele alınan ülkeler için doğal kaynak zenginliğinin, kurumsal yönetişim yapılarını bozması nedeniyle, kişi başına geliri azaltma biçiminde dolaylı etkisine rağmen, pozitif doğrudan etkileri sayesinde halen ekonomik büyümeyi artırabildiği görülmektedir. Bu nedenle sonuçlar kısmi aracılık etkisini ortaya koymaktadır. Yapılan Sobel (1982) testi ile kısmi aracılık etkisinin istatistiki olarak anlamlı olduğu doğrulanmıştır. 


\section{SONUÇ VE DEĞERLENDIRMELER}

Bu çalışmada, MENA ve Hazar bölgesinden seçilen 21 ülke için, kişi başına ham petrol üretiminin temsil ettiği doğal kaynak zenginliği ile kişi başına reel GSYH tarafından ölçülen ekonomik büyüme arasındaki doğrudan ilişkilerde, yönetişim göstergelerinin dolayIı aracılık etkileri 1996-2012 dönemi için ekonometrik olarak araştııılmıştır. Farklı testlerle belirlenen uygun tahminciler kapsamında yapılan ikili ve hiyerarşik panel regresyon analiz bulgularını şu şekilde özetlemek ve değerlendirmek mümkündür: i) Kişi başına ham petrol üretimi, basit ortalaması alınarak tek seride toplulaştırılmış küresel yönetişim göstergelerini anlamlı bir biçimde negatif etkilemektedir. Buna göre petrol üretimine bağlı olarak doğal kaynak zenginliği arttıkça ülkelerin yönetişim göstergeleri bozulma eğilimindedir. Kişi başına ham petrol üretiminin fazla olduğu ülkelerde, ayrıştırılmış alt göstergelerde en çok sırasıyla ifade özgürlüğü ve hesap verebilirlik, düzenleme kalitesi ile hükümetin etkinliğinin bozulma eğiliminde olduğu görülmektedir. ii) Hem ortalama hem de altı alt boyutta incelenen küresel yönetişim göstergelerindeki iyileşmenin kişi başına reel GSYH'yı anlamlı bir biçimde artırdığı belirlenmiştir. Özellikle yolsuzluğun önlenmesi, hükümet etkinliğinin ve düzenleme kalitesinin iyileşmesi kişi başına reel GSYH'yı, dolayısıyla refahı artıracaktır. iii). Yapılan hiyerarşik pa- nel regresyon analizinde kişi başına düşen ham petrol üretiminin, istatistiki olarak anlamlı bir biçimde, kişi başına düşen reel GSYH miktarını olumlu etkilediği, ancak küresel yönetişim göstergelerini olumsuz etkilediği belirlenmiştir. Kişi başına petrol üretiminin, küresel yönetişim göstergelerini kötüleştirerek kişi başına reel GSYH'yı azaltmasına rağmen, halen doğrudan kişi başına reel GSYH'yı iyileştirdiği görülmektedir. $\mathrm{Bu}$ durum küresel yönetişim göstergelerinin kısmi negatif aracı değişken özelliğine işaret etmektedir. Yapılan Sobel testine göre, bu kısmi aracılık etkisi istatistiki olarak anlamlıdır.

Sonuç olarak petrol üretiminin yönetişim göstergelerine olan negatif etkisi giderilebilirse ya da en arzu edilen biçiminde pozitif etkisi sağlanabilirse, kişi başına düşen petrol üretiminin temsil ettiği doğal kaynak zenginliğinin, kişi başına reel GSYH ile temsil edilen büyüme ve dolayısıyla refahı daha da artıracağı görülmektedir. Bu nedenle incelenen ülkeler için hükümet politikalarının doğrudan ekonomik kararlara müdahalelerinin, kurumsal yönetişim göstergelerini iyileştirmeye yönelik uygulamalara kayması gerekliliği kendini göstermektedir. Ayrıca hükümet politikaları ve düzenlemelerine ilişkin uygulama süreçlerinin şeffaf, etkin, hesap verilebilir ve hukuki olmasının önemi de bir kez daha kendini göstermektedir. 


\section{SON NOTLAR}

(1) Testlerin tahmin süreçleri ve ayrıntılı tüm sonuçlar, istenmesi durumunda yazarlardan elde edilebilir.

\section{KAYNAKLAR}

Acemoglu, D., Johnson, S. ve Robinson, J. A. (2001) "The Colonial Origins of Comparative Development: An Empirical Investigation" The American Economic Review, 91(5): 1369-1401.

Acemoglu, D., Johnson, S., Robinson, J. A. ve Thaicharoen, Y. (2003) "Institutioal Causes, Macroeconomic Symptons: Volatility, Crisis and Growth" Journal of Monetary Economics, 50(1): 49-123.

Baltagi, B. H. (2005) Econometric Analysis of Panel Data, 3rd edition, London, John Wiley \& Sons.

Baron, R. M. ve Kenny, D. A. (1986) “The Moderator-Mediator Variable Distinction in Social Psychological Research: Conceptual, Strategic and Statistical Considerations" Journal of Personality and Social Psychology, 51(6): 1173-1182.

Bhagwati, J. N. (1958) "Immiserizing Growth: A Geometrical Note" The Review of Economic Studies, 25(3): 201-205.

Bulte, E. H., Damania, R. ve Deacon, R. T. (2005) "Resource Intensity, Institutions, and Development" World Development, 33(7): 1029-1044.

Busse, M. ve Groening, S. (2011) "The Resources Curse Revisited: Governance and Natural Resources" http://www.csae.ox.ac.uk/conferences/2011-edia/ papers/399-Busse.pdf (13.02.2014).

Caselli, F. (2006) "Power Struggles and the Natural Resource Curse" LSE Research Online Working Paper, http://personal.lse.ac.uk/casellif/papers/curse.pdf (18.02.2014).

Demiral, M. (2014). Gelişmekte Olan Ülkeler, Sanayileşme ve İhracat: Türkiye İle Seçilmiş Ülke Karşılaştırmaları. Yayınlanmamış Doktora Tezi, Adana, Çukurova Üniversitesi SBE.

Feenstra, R. C. (2004) Advanced International Trade: Theory and Evidence. Princeton, Princeton Univ. Press.

Gelb, A.H. (1988) Windfall Gains: Blessing or Curse? New York., Oxford University Press.

Gerring, J. ve Thacker S. C. (2004) "Political Institutions and Corruption: The Role of Unitarism and Parliamentarism" British Journal of Political Science, 34(2): 295-330.

Gylfason, T., Herbertsson, T. T. ve Zoega, G. (1999) "A Mixed Blessing: Natural Resources and Economic Growth" Macroeconomic Dynamics, 3(1999): 204-225.

Gylfason, T. (2001) "Natural Resources, Education, and Economic Development" European Economic Review,
45(2001): 847-859.

Hausmann, R. ve Rigobon, R. (2003) “An Alternative Interpretation for the Resources Curse: Theory and Policy Implications" NBER Working Papers, No. 9424.

Hsiao, C. (2003) Analysis of Panel Data. 2nd ed., Cambridge, Cambridge University Press.

Jensen, N. ve Wantchekon, L. (2004) "Resource Wealth and Political Regimes in Africa" Comparative Political Studies, 37(7): 816-841.

Kolstad, I. ve Soreide, T. (2009) "Corruption in Natural Resource Management: Implications for Policy Makers" Resources Policy, 34(4): 214-226.

Kunicova, J. ve Rose-Ackerman S. (2005) "Electoral Rules and Constitutional Structures as Constraints on Corruption" British Journal of Political Science, 35(4): 573-606.

Lal, D. (1993). The Repressed Economy: Causes, Consequences, Reform. Brookfield, Edward Elgar.

Larsen, R. E. (2006) “Escaping the Resource Curse and the Dutch Disease? When and Why Norway Caught Up With and Forged Ahead of Its Neighbors" American Journal of Economics and Sociology, 65(3): 605-640.

Lederman, D. ve Maloney, W. F. (2007). Natural Resources: Neither Curse Nor Destiny. Palo Alto, Stanford University Press.

Leite, C. ve Weidmann, J. (1999) “Does Mother Nature Corrupt? Natural Resources, Corruption, and Economic Growth" IMF Working Papers, No. 85.

Levin, A., Lin, C. F. ve Chu, C. S. J. (2002) "Unit Root Tests in Panel Data: Asymptotic and Finite-Sample Properties" Journal of Econometrics, 108(1): 1-24.

Mehlum, H., Moene, K. ve Torvik, R. (2006a) "Institutions and The Resource Curse" The Economic Journal, 116(508): 1-20.

Mehlum, H., Moene, K. ve Torvik, R. (2006b) "Cursed by Resources or Institutions?" The World Economy, 29(8): 1117-1131.

Metcalf, G. E. ve Wolfram, C. (2010) "Cursed Resources? Political Conditions and Oil Market Outcomes" NBER Working Papers, No. 16614.

Oomes, N. ve Kalcheva, K. (2007) "Diagnosing Dutch Disease: Does Russia have the symptoms?" BOFIT Discussion Papers, No. 7.

Pesaran, M. H. (2004) "General Diagnostic Tests for Cross Section Dependence in Panels", CESifo Working Papers, No. 1229.

Pessoa, A. (2008) "Natural Resources and Institutions: The Natural Resources Curse Revisited", http:// mpra.ub.uni-muenchen.de/8640/1/MPRA_paper_8640. $\operatorname{pdf}(19.02 .2014)$. 
Petermann, A., Guzman, J. I. ve Tilton, J. E. (2007) "Mining and Corruption". Resources Policy, 32(3): 91103.

Prebisch, R. (1950) “The Economic Development of Latin America and its Principal Problems" Economic Bulletin for Latin America, Vol. 7, New York, United Nations.

Robinson, J. A., Torvik, R. ve Verdier, T. (2006) "Political Foundations of the Resources Curse" Journal of Development Economics, 79(2): 447-468.

Ross, M. L. (2001) "Does Oil Hinder Democracy?” World Politics, 53(3): 325-361.

Rybczynski, T. M. (1955) "Factor Endowments and Relative Commodity Prices" Economica, 22(88): 336341.

Sachs, J. D. ve Warner, A. M. (1997) "Natural Resource Abundance and Economic Growth" NBER Working Paper Series, No. 5398.

Sachs, J. D. ve Warner, A. M. (1999) "The Big Push, Natural Resource Booms and Growth" Journal of Development Economics, Vol. 59: 43-76.

Sachs, J. D. ve Warner, A. M. (2001) "The Curse of Natural Resources" European Economic Review, 45(4-6):

\section{7-838.}

Singer, H. W. (1950) "The Distribution of Gains between Investing and Borrowing Countries" American Economic Review, Vol. 15: 473-485.

Sobel, M. E. (1982) "Asymptotic Intervals for Indirect Effects in Structural Equations Models" Sociological Methodology, Vol. 13: 290-312.

Wantchekon, L. (1999) "Why do Resource Dependent Countries Have Authoritarian Governments?" Journal of African Finance and Economic Development, 5(2): 57-77.

Williams, A. (2011) "Shining a Light on the Resources Curse: An Empirical Analysis of the Relationship Between Natural Resources, Transparency, and Economic Growth” World Development, 39(4): 490-505.

Yang, B. (2009) "Resource Curse: The Role of Institutions Versus Policies" Applied Economics Letters, 17(1): 61-66.

WB-WGI (2014), http://info.worldbank.org/governance/wgi/index.aspx\#home (04.02.2014).

US-EIA (2014), http://www.eia.gov/cfapps/ipdbproject/IEDIndex3.cfm (04.02.2014). 